\title{
MODIFIKASI MESIN MOTOR RODA DUASERI BEAT ESP 2017 HEMAT ENERGI DENGAN METODE STROKE UP DAN BORE UP
}

\author{
Kholis Nur Faizin ${ }^{1)}$, Achmad Aminudin ${ }^{2)}$ \\ ${ }^{1)}$ Mesin otomotif,Politeknik Negeri Madiun, Jalan Serayu no 84, Madiun, 63133 \\ ${ }^{2}$ Mesin Otomotif, Politeknik Negeri Madiun, Jalan Serayu no 84, Madiun, 63133 \\ E-mail: kholis@pnm.ac.id
}

\begin{abstract}
This research is motivated by the depletion of fuel oil supplies in Indonesia, while the needs of the public are increasingly reminded. This energy also cannot be updated. It takes thousands or even millions of years of the time needed by nature to form the fuel oil. One of its efforts is to reduce fuel consumption. The compiler effort in supporting the savings program is to modify the vehicle. The research objective of this is to find out how to modify the engine to be more fuel efficient and know how to make noise levels not more than $90 \mathrm{~dB}$. This study uses the method of stroke up, bore up and low profile camshaft, so the engine character becomes overstroke. Overstroke means the stroke distance is longer than the bore. This vehicle will produce the advantages of fast starting and large and strong torsion and the use of fuel can be minimized. This research is expected to be able to optimize combustion in the combustion chamber so as to reduce fuel consumption and noise.
\end{abstract}

Keywords: stroke up, bore up, engine Power

\begin{abstract}
Abstrak
Penelitian ini dilatarbelakangi oleh persediaan bahan bakar minyak di Indonesia yang semakin menipis, sedangkan kebutuhan masyarakat semakin meningat. Energi tersebut juga tidak dapat diperbarui. Butuh ribuan bahkan jutaan tahun waktu yang dibutuhkan alam untuk membentuk bahan bakar minyak tersebut. Salah satu upayanya adalah untuk mengurangi konsumsi bahan bakar minyak. Usaha penyusun dalam mendukung program penghematan tersebut adalah melakukan modifikasi terhadap kendaraan. Tujuan penelitian dari ini, yaitu ingin mengetahui cara memodifikasi mesin agar menjadi lebih hemat bahan bakar dan mengetahui cara agar tingkat kebisingan suara tidak lebih dari $90 \mathrm{~dB}$. Penelitian ini menggunakan metode stroke up, bore up dan camshaft low profil, sehingga karakter mesin menjadi overstroke. Overstroke berarti jarak stroke lebih panjang dari bore. Kendaraan ini akan menghasilkan kelebihan tarikan awal yang cepat dan torsi yang besar dan kuat serta penggunaan bahan bakar dapat diminimalisir. Penelitian ini diharapkan mampu mengoptimalkan pembakaran di dalam ruang bakar sehingga mereduksi konsumsi bahan bakar dan kebisingan.
\end{abstract}

Kata Kunci: stroke up, bore up, Daya

\section{PENDAHULUAN}

Persediaan bahan bakar minyak di Indonesia yang semakin menipis, sedangkan kebutuhan masyarakat semakin meningat. Energi tersebut juga tidak dapat diperbarui. Butuh ribuan bahkan jutaan tahun waktu yang dibutuhkan alam untuk membentuk bahan bakar minyak tersebut. Salah satu upayanya adalah untuk mengurangi konsumsi bahan bakar minyak. Usaha penyusun dalam mendukung program penghematan tersebut adalah melakukan modifikasi terhadap kendaraan.

Hasil penelitian Paridawati (2014) Jurusan Magister Teknik Mesin, Fakultas Teknik,
Universitas Diponegoro, mesin kendaraan bermotor mempunyai engine map yang dapat diubah-ubah mappingnya sesuai keinginan pemilik. Salah satu cara untuk mendapatkan map terbaik tentu saja diperlukan cara khusus agar tidak melakukan kesalahan dalam melakukan perubahan tersebut. Artificial neural Network (ANN), saat ini sangat memegang peranan penting dalam melakukan optimasi terhadap efisiensi kinerja mesin, khususnya penurunan konsumsi bahan bakar. Penelitian ini, dilakukan dengan tujuan untuk melakukan simulasi untuk mendapatkan kinerja mesin yang efisien. pertama-tama akan dilakukan pengambilan sejumlah data menggunakan scanner 
pada engine control unit (ECU) untuk mengetahui engine map saat ini (existing). Selanjutnya adalah melakukan optimasi menggunakan pemodelan menggunakan Artifcial Neural Network (ANN). Pada simuasi ANN, digunakan kecepatan mesin, bukaan throttle, ignition timing dan time injection sebagai input, sedangkan output adalah torsi dan konsumsi bahan bakar. Optimasi dilakukan pada beberapa kondisi, yaitu posisi ignition timing maju $10 \%, 15 \%, 20 \%, 25 \%, 30 \%$, 35\%, dan $40 \%$ serta mundur $10 \%, 15 \%$ dan $20 \%$. Hasil optimasi ANN menunjukkan hasil yang maksimal pada posisi ignition timing maju 20\%, yaitu menurunkan konsumsi bahan bakar sampai $12 \%$, sedang pada pisisi ignition timing yang lain, terjadi peningkatan konsumsi bahan bakar, sehingga dapat mengurangi efisiensi mesin.

Akan tetapi, pengubahan dimensi ruang bakar belum tersentuh sama sekali terhadap penghematan bahan bakar dan kebisingan. Untuk itu peneliti tertarik memodifikasi mesin motor roda dua dengan menggunakan metode stroke up dan bore up tetapi hemat bahan bakar.

\section{METODE PENELITIAN}

\section{Proses Perencanaan}

Proses perencanaan salah satunya dengan menggunakan perhitungan rumus yang ada di dalam materi teoritis dan disesuaikan dengan kebutuhan mesin hasil rakitan ulang honda beat Esp 2017. Dalam proses perencanaan ini penyusun memodifikasi beberapa komponen seperti: panjang langkah crankshaft, diameter piston, perbandingan kompresi, lift camshaft.

\section{Perencanaan Panjang Langkah Crankshaft}

Penggunaan crankshaft standar honda beat Esp 2017 yang telah digeser langkahnya sebanyak 3,5 $\mathrm{mm}$ serta connecting rod menggunakan Honda C 70 .

\section{Diameter Piston}

bore up dengan cara mengganti piston kit 52,4 $\mathrm{mm}$ (standar $50 \mathrm{~mm}$ ) serta boring yang lebih besar menyesuaikan diameter piston.

\section{Perencanaan Lift Camshaft}

Pengurangan lift camshaft sebesar 1-3 mm pada 3 camshaft yang disediakan. Jadi ketiga camshaft yang disediakan penyusun yaitu : camshaft-1 mm, camshaft-2 $\mathrm{mm}$ dan camshaft-3 $\mathrm{mm}$. Dari ketiga perbandingan tersebut diuji mana yang paling hemat bahan bakar.
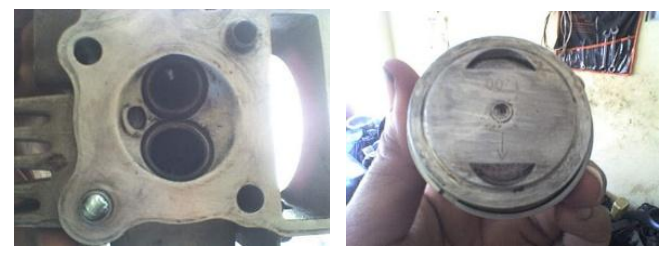

Gambar.1 konsep perubahan

Sumber: Rancangan dari sistem, 2018

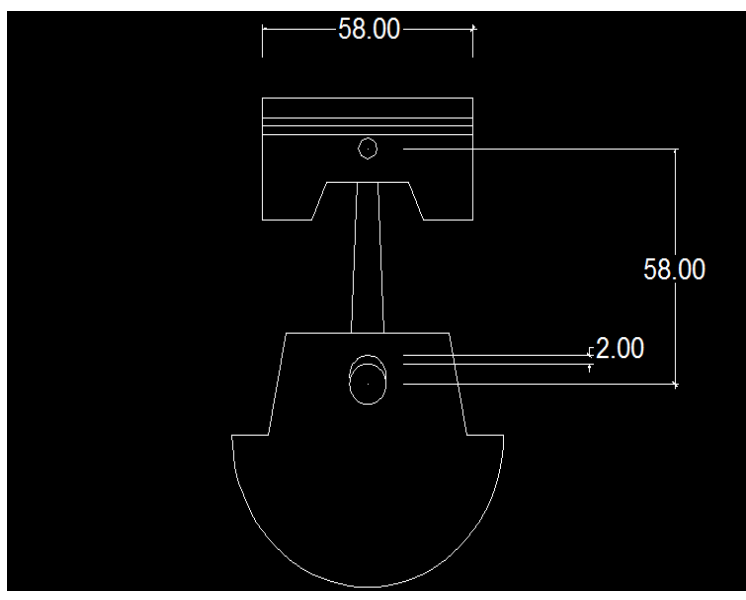

Gambar.2 rancangan stroke up

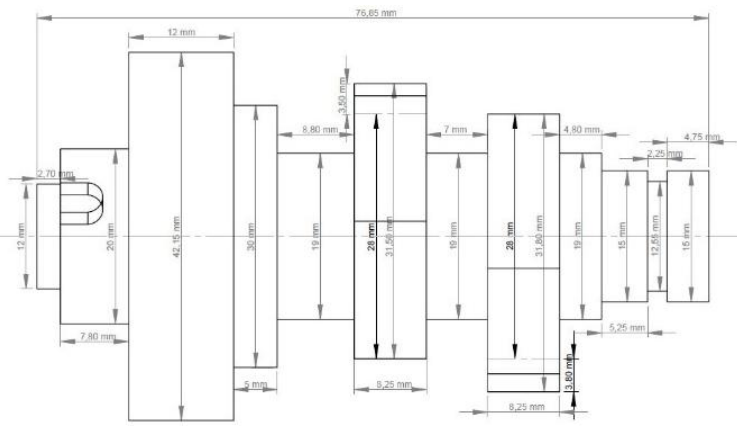

Gambar.3 rancangan camshaft

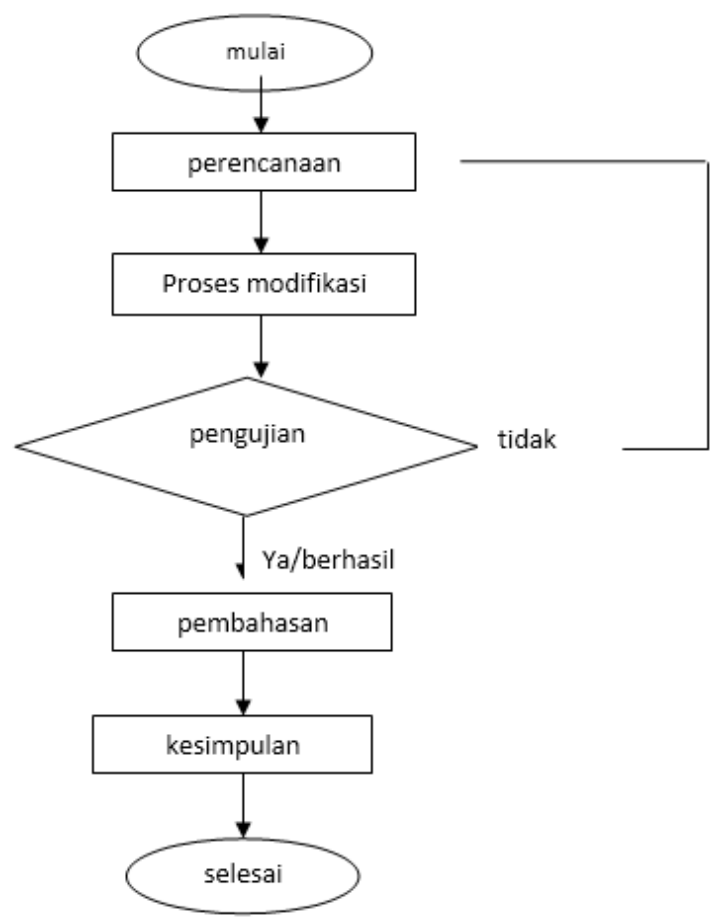

Gambar.4 Flowchart penelitian

Sumber: Rancangan dari sistem, 2018 
HASIL DAN PEMBAHASAN

Tabel 4.1. Hasil pengukuran derajat camshaft

\begin{tabular}{|c|c|c|}
\hline \multicolumn{3}{|c|}{ Camshaft Profile } \\
\hline \multirow[t]{2}{*}{ Intake } & Buka & $\begin{array}{c}13^{\circ} \text { setelah } \\
\text { TMA }\end{array}$ \\
\hline & Tutup & $\begin{array}{l}26^{\circ} \text { setelah } \\
\text { TMB }\end{array}$ \\
\hline \multirow[t]{2}{*}{ Exhaust } & Buka & $\begin{array}{c}16^{\circ} \text { sebelum } \\
\text { TMB }\end{array}$ \\
\hline & Tutup & $\begin{array}{c}7^{\circ} \text { sebelum } \\
\text { TMA }\end{array}$ \\
\hline \multirow[t]{3}{*}{ Durasi } & Intake & $\begin{array}{c}77^{\circ}+90^{\circ}+26^{\circ} \\
=193^{\circ}\end{array}$ \\
\hline & Exhaust & $\begin{array}{c}16^{\circ}+90^{\circ}+83^{\circ} \\
=189^{\circ}\end{array}$ \\
\hline & Total & $382^{\circ} / 2=191^{\circ}$ \\
\hline \multirow[t]{2}{*}{ Lobe Center } & In & $\begin{array}{l}\left(193^{\circ} / 2\right)-(- \\
\left.13^{\circ}\right)=109,50^{\circ}\end{array}$ \\
\hline & Ex & $\begin{array}{l}\left(189^{\circ} / 2\right)-(- \\
\left.7^{\circ}\right)=101,50^{\circ}\end{array}$ \\
\hline \multicolumn{2}{|c|}{ LSA } & $\begin{array}{c}211^{\circ} / 2= \\
105,50^{\circ}\end{array}$ \\
\hline \multicolumn{2}{|c|}{ Overlap } & $\begin{array}{c}\left(-7^{\circ}\right)+\left(-13^{\circ}\right)= \\
-20^{\circ}\end{array}$ \\
\hline \multirow[t]{2}{*}{ Lift } & In & $3,80 \mathrm{~mm}$ \\
\hline & Ex & $3,50 \mathrm{~mm}$ \\
\hline
\end{tabular}

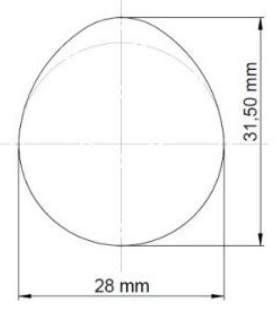

LOBE EXHAUST

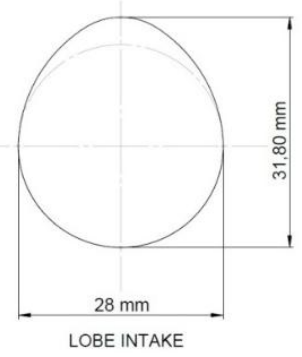

LOBE INTAKE
Gambar.5 Tampilan Depan Dari poros camchaft

Sumber: Hasil Pembuatan Sistem, 2018

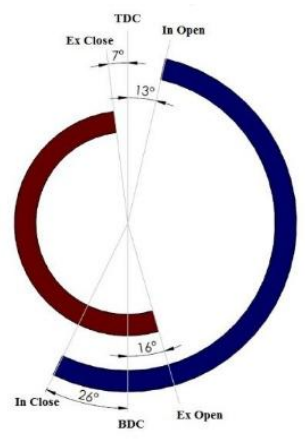

Gambar.6 Hasil pengukuran camshaft Sumber: Hasil Pembuatan Sistem, 2018

\section{Daya}

Tabel 4.2 Data Daya Untuk Mesin Standar

\begin{tabular}{|l|lr|r|r|}
\hline No. & $\begin{array}{l}\text { Putaran } \\
\text { (Rpm) }\end{array}$ & Mesin & $\begin{array}{l}\text { Daya } \\
\text { (hp) }\end{array}$ & \multicolumn{1}{l|}{$\begin{array}{l}\text { Torsi } \\
\text { (Nm) }\end{array}$} \\
\hline 1 & 3500 & 4.1 & 8.25 \\
\hline 2 & 4000 & 4.7 & 8.41 \\
\hline 3 & 4500 & 5.3 & 8.3 \\
\hline 4 & 4683 & 5.6 & 8.49 \\
\hline 5 & 5000 & 5.9 & 8.36 \\
\hline 6 & 5500 & 6.2 & 7.95 \\
\hline 7 & 6000 & 6.7 & 7.87 \\
\hline 8 & 6500 & 6.9 & 7.49 \\
\hline 9 & 7000 & 7.4 & 7.48 \\
\hline 10 & 7500 & 7.5 & 7.04 \\
\hline 11 & 7580 & 7.7 & 7.14 \\
\hline 12 & 8000 & 7.3 & 6.44 \\
\hline 13 & 8500 & 7.1 & 5.87 \\
\hline 14 & 9000 & 7 & 5.1 \\
\hline
\end{tabular}

Tabel 4.3 Data Daya Untuk Mesin modifikasi

\begin{tabular}{|l|lr|r|r|}
\hline No. & $\begin{array}{l}\text { Putaran } \\
(\mathrm{Rpm})\end{array}$ & Mesin & \multicolumn{1}{l|}{$\begin{array}{l}\text { Daya } \\
\text { (hp) }\end{array}$} & \multicolumn{1}{l|}{$\begin{array}{l}\text { Torsi } \\
(\mathrm{Nm})\end{array}$} \\
\hline 1 & 3500 & 4.8 & 9.74 \\
\hline 2 & 4000 & 7.1 & 12.63 \\
\hline 3 & 4500 & 8.5 & 13.41 \\
\hline 4 & 5000 & 9.4 & 13.4 \\
\hline 5 & 5397 & 10.4 & 13.72 \\
\hline 6 & 5500 & 10.6 & 13.68 \\
\hline 7 & 6000 & 11.2 & 13.25 \\
\hline 8 & 6500 & 11.2 & 12.15 \\
\hline 9 & 6786 & 11.4 & 11.89 \\
\hline 10 & 7000 & 10.9 & 11.04 \\
\hline 11 & 7500 & 10.3 & 9.74 \\
\hline 12 & 8000 & 9.8 & 8.62 \\
\hline 13 & 8500 & 8.6 & 7.16 \\
\hline 14 & 9000 & 7.4 & 5.82 \\
\hline
\end{tabular}




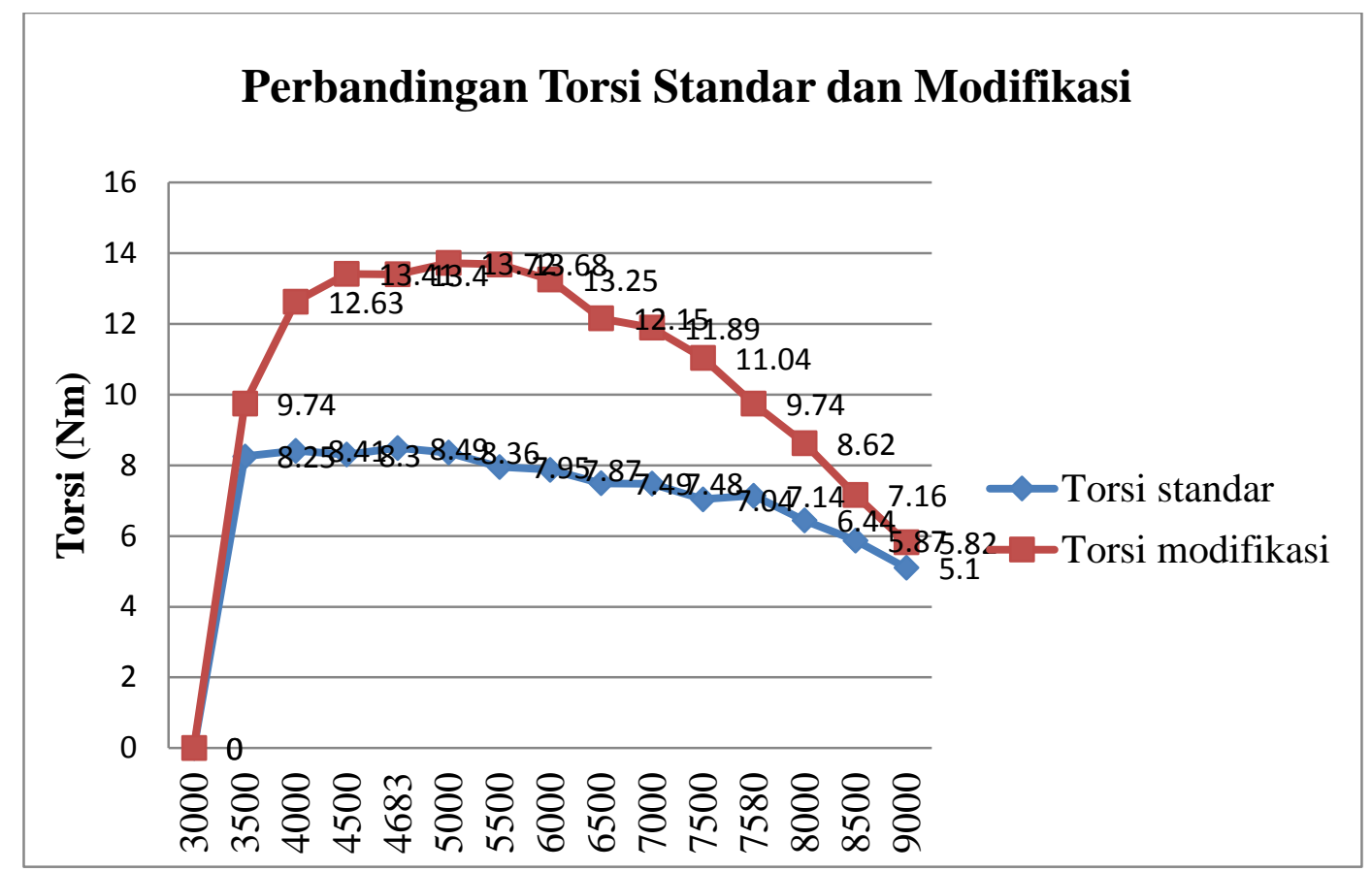

Gambar.7 Tampilan Grafik daya

Sumber: Hasil Pembuatan Sistem, 2018

Pada pengujian standar diperoleh nilai torsi maksimal pada putaran mesin $4.683 \mathrm{rpm}$, yaitu sebesar $8,49 \mathrm{Nm}$. Sedangkan pada pengujian modifikasi diperoleh nilai maksimal torsi pada putaran mesin $5.397 \mathrm{rpm}$, yaitu sebesar 13,72 Nm

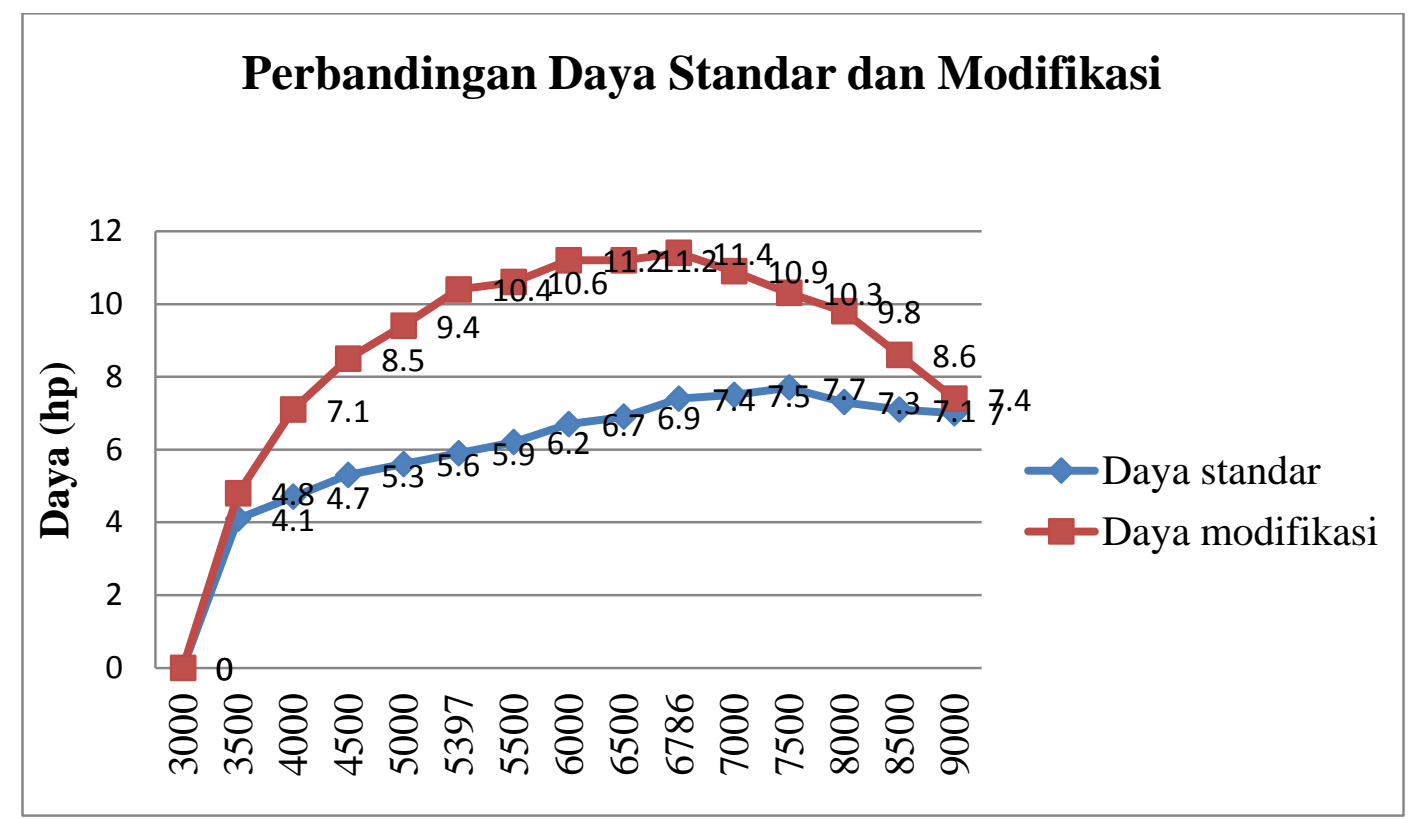

Gambar.8 Pengujian Sistem Monitoring Kualitas Air Danau

Sumber: Hasil Pembuatan Sistem, 2018

Pada pengujian standar diperoleh nilai daya maksimal pada putaran mesin $7.580 \mathrm{rpm}$, yaitu sebesar 7,7 hp. Sedangkan pada pengujian modifikasi diperoleh nilai maksimal daya pada putaran mesin $6.786 \mathrm{rpm}$, yaitu sebesar 11,4 hp.

\section{PEMBAHASAN}

1. Daya

Daya merupakan besarnya kerja motor selama waktu tertentu. Daya pada sepeda motor dapat dihitung menggunakan alat dynotest. Perencanaan 
modifikasi stroke up crankshaft ini sudah sesuai dengan kebutuhan kendaraan Honda Beat Esp 2017. menunjukan nilai daya lebih besar didapatkan pada poros engkol modifikasi yaitu $11,4 \mathrm{hp}$ sedangkan penentuan daya dengan teori daya diperoleh 11,20hp. Pengujian secara alat dan teori sudah hampir mendekati.Perbedaan daya yang dihasilkan karena adanya perubahan pada panjang langkah yang dilakukan pada poros engkol dengan menggeser posisi big end connecting rod menjadi lebih tinggi.Hal ini akan membuat rasio kompresi lebih tinggi. Bila rasio kompresi dipertinggi, tekanan pembakaran akan bertambah dan dari mesin akan diperoleh output yang besar. Dalam hal ini penguji menggunakan bahan bakar pertamax, supaya daya yang dihasilkan besar dan tidak menimbulkan detonasi, sehingga tahan terhadap tekanan kompresi. Dari pengujian tersebut dapat disimpulkan hubungan antara putaran mesin dan horse power mesin berubah - ubah tergantung dari kecepatan putaran mesin. Mesin dengan putaran tinggi, tenaga yang dihasilkan juga besar tapi jika putaran terlalu tinggi tenaga yang dihasilkan akan menurun. Jika pada putaran tertentu tenaga maksimum dihasilkan, maka hal itu disebut "maksimum power". Terlihat perbedaan signifikan mulai dari rpm bawah menengah sampai atas.

\section{Torsi}

Torsi merupakan kemampuan mesin untuk menggerakkan kendaraan dari kondisi diam hingga berjalan. Berdasarkan percobaan yang telah dilakukan diperoleh perbedaan torsi yang dihasilkan masing-masing poros engkol. Pada grafik menunjukkan nilai lebih besar didapatkan pada poros engkol modifikasi dibandingkan dengan poros engkol standar yaitu $13,72 \mathrm{Nm}$ sedangkan jika dihitung menggunakan teori torsi hasilnya 13,71 $\mathrm{Nm}$, pengujian secara alat dan teori sudah hampir mendekati. Perbedaan torsi yang dihasilkan karena adanya perbedaan rasio kompresi. Rasio kompresi menjadi lebih tinggi karena adanya perubahan big end connecting rod pada poros engkol menjadi lebih tinggi. Oleh karena itu motor yang lingkaran engkolnya besar, tenaga yang dihasilkan akan lebih besar dibanding motor yang berdiamater engkol kecil,yang berarti dengan langkah yang panjang maka akan menghasilkan momen yang lebih besar. Pada data pengujian tabel dan grafik dapat diketahui perubahan torsi maksimalnya, dapat disimpulkan bahwa dengan meningkatnya kemampuan mesin maka gaya gerak yang dihasilkan juga meningkat.

\section{SIMPULAN}

Dari hasil perbandingan di atas hasil data daya dan torsi tertinggi diperoleh pada data modifikasi, hal ini dikarenakan massa campuran udara dan bahan bakar lebih besar dari kondisi standar sehingga laju aliran gasnya lebih sempurna. Pada grafik pengujian daya dan torsi secara aktual pada mesin standar dan modifikasi terjadi penurunan setelah mencapai kondisi tertinggi, hal tersebut dikarenakan oleh karakteristik dari motor bakar bensin pada saat rpm tinggi suplay campuran bahan bakar dan udara yang masuk ke dalam ruang bakar tidak mampu mengimbangi kecepatan piston pada rpm tinggi sehingga pada saat mencapai kondisi daya dan torsi tertinggi pada rpm tertentu grafik daya dan torsi cenderung mengalami penurunan.

\section{DAFTAR PUSTAKA}

[1] Haynes Publishing. Gayiler Bob. 2002. BREATHING-THE INDUCTION SYSTEM AIR BOXIES AND CLEANERS. USA

[2] Haynes Publishing. Gayiler Bob. 2002. COMBUSTION-THE POWER STROKE. USA

[3] Haynes Publishing. Gayiler Bob. 2002. ENGINE RELIABILITY. USA

[4] Haynes Publishing. Gayiler Bob. 2002. POWER. USA

[5] Haynes Publishing. Gayiler Bob. 2002. THE CAMSHAFT. USA

[6] Haynes Publishing. Gayiler Bob. 2002. THE EXHAUST SYSTEM. USA

[7] Haynes Publishing. Graham Bell. A. 2006. FOUR-STROKE PERFORMACE TUNING, (THIRD EDITION). California, North America

[8]http://78deka.com/2014/04/13/overboreoverstroke-overbore/ Diakses pada tanggal 23 Mei 2017, pukul 20.01 wib

[9]http://id.wikipedia.org/wiki/Berkas:Piston_rings .jpg Diakses pada tanggal 23 Mei 2017, pukul $20.34 \mathrm{wib}$

[10]http://ratmotorsport.wordpress.com/2013/11/11 /durasi-lift-noken-as/ Diakses pada tanggal 20 Mei 2017, pukul 20.51 wib

[11] http://www.laskar-suzuki.com/2012/04/fungsiklepkatupvalve-dan.html Diakses pada tanggal 2 Juni 2017, pukul 21.16 wib

[12] Ir. Witantyo M.Eng.Sc, DKK. 2014. Regulasi Teknis IEMC. ITS, Surabaya 